\title{
The location of $\mathrm{Mn}$ and $\mathrm{Fe}$ in axinite-(Fe) from Nandan, China determined by anomalous $\mathrm{X}$-ray scattering (AXS)
}

\author{
Daitaro KitAharA ${ }^{*}$, Hiroshi ArimA ${ }^{* *}$, Toru Kawamata* ${ }^{*}$ Kazumasa SugiYamA* and Takashi Mikouchi ${ }^{* * *}$ \\ *Institute for Materials Research (IMR), Tohoku University, Sendai 980-8577, Japan \\ ${ }^{* *}$ Neutron Science and Technology Center, CROSS, Ibaraki 319-1106, Japan \\ ${ }^{* * *}$ The University Museum, The University of Tokyo, Tokyo 113-0033, Japan
}

\begin{abstract}
The distribution of $\mathrm{Mn}$ and $\mathrm{Fe}$ in axinite-(Fe) from Nandan, China, with the structural formula $\mathrm{Ca}_{2}\left(\mathrm{Fe}_{0.565}\right.$ $\left.\mathrm{Mn}_{0.33} \mathrm{Mg}_{0.08} \mathrm{Ca}_{0.025}\right)\left(\mathrm{Al}_{1.94} \mathrm{Fe}_{0.06}\right) \mathrm{Si}_{4} \mathrm{BO}_{15}(\mathrm{OH}), Z=2$, space group $P \overline{1}, a=7.1488(4) \AA, b=9.1970(4) \AA, c=$ 8.9688(3) $\AA, \alpha=91.708(6)^{\circ}, \beta=98.099(6)^{\circ}$, and $\gamma=77.201(5)^{\circ}$, was determined by anomalous X-ray scattering measurements at $\mathrm{Mn}$ and $\mathrm{Fe} K$-absorption edges. The elemental distribution map of Mn obtained by AXS analysis indicates the residence of $\mathrm{Mn}$ at the $Y$ site. Conversely, the elemental map of Fe shows the location of $\mathrm{Fe}$ at both the $Y$ and $Z 1$ sites. XANES analysis clarifies the progressive incorporation of $\mathrm{Fe}^{3+}$ with decreasing $\mathrm{Al}$ content in axinite- $(\mathrm{Fe})$. These experimental results readily suggest the substitution of $\mathrm{Al}^{3+}$ by $\mathrm{Fe}^{3+}$ at the $Z 1$ site.
\end{abstract}

Keywords: Axinite, XAFS, Anomalous X-ray scattering

\section{INTRODUCTION}

The axinite group minerals typically occur inskarn and other contact metamorphic rocks with B-rich and relatively Al-poor environments (e.g., Grew, 1996). The general formula, $(\mathrm{Ca}, \mathrm{Mn})_{2}(\mathrm{Fe}, \mathrm{Mn}, \mathrm{Mg}) \mathrm{Al}_{2} \mathrm{Si}_{4} \mathrm{BO}_{15}(\mathrm{OH})$, was proposed by Sanero and Gottardi (1968) and later revised by Lumpkin and Ribbe (1979) and Andreozzi et al. (2004). In this paper, we utilize the site nomenclature according to the generalized structural formula: ${ }^{\mathrm{V}}[X 1, X 2$, $Y, Z 1, Z 2]_{5}{ }^{\mathrm{IV}}[T 1, T 2, T 3, T 4, T 5] \mathrm{O}_{15}(\mathrm{O}, \mathrm{OH})$, where superscript VI and IV are coordination numbers; $X 1=\mathrm{Ca}$, $X 2=\mathrm{Ca}, Y=\mathrm{Fe}^{2+}, \mathrm{Mn}^{2+}, \mathrm{Mg}, Z 1=\mathrm{Al}, \mathrm{Fe}^{3+}, Z 2=\mathrm{Al}$, $\mathrm{Fe}^{3+}, T 1-T 4=\mathrm{Si}$, and $T 5=\mathrm{B}$. The three kinds of endmembers for axinite minerals are classified according to the dominant cation at the $Y$ site. Axinite- $(\mathrm{Fe})$, axinite$(\mathrm{Mn})$, and axinite- $(\mathrm{Mg})$ indicate the most dominant $\mathrm{Fe}$, $\mathrm{Mn}$, and $\mathrm{Mg}$ at the $Y$ site, respectively. Tinzenite, with 2 $\leq \mathrm{Ca} \leq 4$ apfu, prefers the location of Mn at both the $X 2$ and $Y$ sites (Basso et al., 1973; Belokoneva et al., 1997, 2001).

The crystal structure of axinite was determined by Takéuchi et al. (1974), and the structural details were well

doi:10.2465/jmps. 190110

K. Sugiyama, kazumasa@imr.tohoku.ac.jp Corresponding author demonstrated by Basso et al. (1973). Understanding the crystallographic location of transition metal elements is of great interest in the axinite group of minerals, since the distribution of $\mathrm{Mg}, \mathrm{Mn}$, and $\mathrm{Fe}$ is a key to classify the minerals. According to a variety of studies on the solidsolutions of axinite-(Mn) and axinite- $(\mathrm{Fe})$, divalent iron $\mathrm{Fe}^{2+}$ and manganese $\mathrm{Mn}^{2+}$ are located at the $Y$ site, whereas trivalent iron $\mathrm{Fe}^{3+}$ prefers the smaller $Z 1$ site (Andreozzi et al., 2000a, 2004). The reports also demonstrate that an increase in the Mn content encourages the progressive incorporation of $\mathrm{Fe}^{3+}$ at the $Z 1$ site. The chemical analysis and corresponding results of the ordinary single crystal X-ray diffraction well support above discussions, nevertheless direct evidence with respect to the distribution of $\mathrm{Mn}$ and $\mathrm{Fe}$ in the axinite structure has not been reported.

In this paper, we demonstrate the distribution of $\mathrm{Mn}$ and $\mathrm{Fe}$ in axinite- $(\mathrm{Fe})$ from Nandan Country, China using the results of X-ray absorption fine structure (XAFS) and anomalous X-ray scattering (AXS). The results of ordinary single-crystal $\mathrm{X}$-ray diffraction assisted by the structural information around $\mathrm{Mn}$ and $\mathrm{Fe}$ are also discussed.

\section{EXPERIMENTAL}

The present axinite-(Fe) specimen found at Nandan 
Table 1. Chemical compositions of three axinite-(Fe) samples

\begin{tabular}{lccc}
\hline & $\begin{array}{c}\text { Nandan } \\
(\text { Nan-C) }\end{array}$ & $\begin{array}{c}\text { Obira } \\
(\text { Obi-J) }\end{array}$ & $\begin{array}{c}\text { Khapalu } \\
(\text { Kha-P) }\end{array}$ \\
\hline $\mathrm{CaO}\left(\mathrm{wt}^{2}\right)$ & $19.68-20.00$ & $18.04-20.20$ & $19.69-20.40$ \\
$\mathrm{MnO}$ & $3.43-4.66$ & $1.33-9.51$ & $2.42-3.41$ \\
$\mathrm{FeO}$ & $7.42-8.29$ & $3.61-9.57$ & $7.09-7.94$ \\
$\mathrm{MgO}$ & $0.39-0.90$ & $0.14-1.14$ & $0.63-1.66$ \\
$\mathrm{Al}_{2} \mathrm{O}_{3}$ & $17.06-17.52$ & $15.68-18.26$ & $16.92-18.39$ \\
$\mathrm{SiO}_{2}$ & $42.81-43.72$ & $41.44-43.25$ & $42.51-45.95$ \\
\hline \multicolumn{4}{c}{$a p f u[\Sigma(\mathrm{Ca}+\mathrm{Mn}+\mathrm{Fe}+\mathrm{Mg}+\mathrm{Al})=10]$} \\
$\mathrm{Ca}$ & $4.05(3)$ & $3.99(1)$ & $4.06(2)$ \\
$\mathrm{Mn}$ & $0.66(2)$ & $0.67(5)$ & $0.48(2)$ \\
$\mathrm{Fe}$ & $1.25(2)$ & $1.28(3)$ & $1.19(2)$ \\
$\mathrm{Mg}$ & $0.16(2)$ & $0.18(1)$ & $0.28(3)$ \\
$\mathrm{Al}$ & $3.88(1)$ & $3.87(2)$ & $3.99(2)$ \\
$\mathrm{Si}$ & $8^{*}$ & $8^{*}$ & $8^{*}$ \\
${ }^{*}$ Fixed (see text).
\end{tabular}

County, Hechi Prefecture, Guangxi Zhuang Autonomous Region, China (Nan-C), consists of clove-brown-colored crystals with the typical axe-shaped habits. An electron probe micro-analyzer (EPMA: JEOL JXA-8530v at the University of Tokyo) was employed for the chemical analysis. The results are listed in Table 1, together with those for axinite samples from Obira mine, Bungo-Ohno City, Oita Prefecture, Japan (Obi-J) and Khapalu, Ganache District, Gilgit-Baltistan, Pakistan (Kha-P). Among the examined elements, the amounts of $\mathrm{Na}_{2} \mathrm{O}, \mathrm{K}_{2} \mathrm{O}$, and $\mathrm{TiO}_{2}$ were lower than their respective detection limits. No further analysis of the components of $\mathrm{B}_{2} \mathrm{O}_{3}$ and $\mathrm{H}_{2} \mathrm{O}$ was performed in this study.

Transmission XAFS spectra of Mn and Fe $K$-absorption edges were measured at BL-7C, Institute of Material Structure Science (IMSS), High Energy Accelerator Research Organization (KEK), Tsukuba, Japan. The X-rays were monochromatized with a Si (111) double-crystal monochromator. We also measured the spectrum for $\mathrm{Mn}^{2+}$ (rhodonite $\mathrm{MnSiO}_{3}$, and chemical regent $\mathrm{MnO}$ ), $\mathrm{Mn}^{3+}$ (chemical regent $\mathrm{Mn}_{2} \mathrm{O}_{3}$ ), $\mathrm{Fe}^{2+}$ (ilmenite $\mathrm{FeTiO}_{3}$ and chemical reagent $\mathrm{FeO}$ ), and $\mathrm{Fe}^{3+}$ (chemical reagent $\mathrm{Fe}_{2} \mathrm{O}_{3}$ ), respectively. The corresponding XANES spectra were extracted from the measured spectra using the Athena and Artemis software package (Ravel and Newville, 2005).

The anomalous X-ray scattering (AXS) study at Mn and $\mathrm{Fe} K$-absorption edges was performed at BL-6C, IMSS. Intensity data were collected using a horizontaltype four circle diffractometer (Rigaku AFC-5). A pair of incident energies, which correspond to $25 \mathrm{eV}$ and $150 \mathrm{eV}$ below each $K$-absorption edge (Mn, $6539 \mathrm{eV} ; \mathrm{Fe}, 7112$ $\mathrm{eV})$, were employed for the present measurements. These energies were tuned using a double-crystal Si (111) monochromator. The monochromatic incident beam was cir- cularly polarized by a transmission-type phase retarder of (001) diamond (Hirano et al., 1995). After Lorentz and polarization corrections, an absorption correction was performed based on the size of the specimen while referring to the measured $\psi$-scan data. Linear absorption coefficients for the X-ray energies employed in this AXS study were calculated by using the theoretically calculated mass absorption coefficients (Waseda, 1984). The detailed procedure for AXS analysis has been well described in previous studies (Wulf, 1990; Sugiyama et al., 2010; Togashi et al., 2011). 804 and 794 reflection pairs in the full reciprocal space up to $\sin \theta / \lambda=0.44$ were measured at the $\mathrm{Mn}$ and $\mathrm{Fe} K$-absorption edges, respectively, and employed for the present data processing.

Ordinary single-crystal X-ray diffraction using MoK $\alpha$ radiation was also performed in this study. Intensity measurement was carried out using an X-ray diffractometer equipped with an imaging plate and a conventional X-ray tube and Lorentz, polarization and absorption corrections were conducted (Rigaku R-AXIS RAPID). Scattering factors for neutral atoms and anomalous dispersion coefficients were adopted from Volume C of the International Tables for Crystallography (1992). The leastsquares refinement was carried out using the software program SHELXL (Sheldrick, 2008) implemented in WinGX (Farrugia, 2012). Detailed information on the data collectionis listed in Table 2.

\section{STRUCTURE ANALYSIS}

The crystal structure of axinite is described as an alternation of a tetrahedral layer and octahedral layer in Figure 1 (Takéuchi et al., 1974; Andreozzi et al., 2000b). A tetrahedral layer is composed of isolated $\mathrm{B}_{2} \mathrm{Si}_{8} \mathrm{O}_{30}\left[T 5_{2}(T 1\right.$, $T 2, T 3, T 4)_{8} \mathrm{O}_{30}$ ] planar units, where the two kinds of di-silicate groups of $T 1 T 2 \mathrm{O}_{7}$ and $T 3 T 4 \mathrm{O}_{7}$ are connected by two $T 5$ tetrahedra. Another octahedral layer consists of a six-fold finite chain of octahedra with a sequence of $Y$ $Z 1-Z 2-Z 2-Z 1-Y$ linked by heavily distorted octahedra around $X 1$ and $X 2$, filled by Ca with relatively large ionic radii. The positional parameters given by Andreozzi et al. (2004) were used as starting parameters for a full-matrix least-squares refinement. As for the octahedral sites, $X 1$ and $X 2$ sites are modeled by the full occupation of $\mathrm{Ca}$, the $Y$ site is modeled by the mixed occupation $\mathrm{Mg} / \mathrm{Fe}$, and $Z 1$ and $Z 2$ are modeled by Al. $T 1, T 2, T 3$, and $T 4$ were modeled by the full occupation of $\mathrm{Si}$, and $T 5$ was fully occupied by B. The obtained structural parameters gave average distances of between 1.62 and $1.63 \AA$ for the tetrahedral $T 1, T 2, T 3$, and $T 4$ sites. This result readily supports the full occupation of Si at these four tetrahedral sites, together with the almost stoichiometric silicon for 
Table 2. Crystal data and structural analysis summary of axinite- $(\mathrm{Fe})$ from Nan-C

\begin{tabular}{ll}
\hline Structural model & $\mathrm{Ca}_{2}\left(\mathrm{Fe}_{0.565} \mathrm{Mn}_{0.33} \mathrm{Mg}_{0.08} \mathrm{Ca}_{0.025}\right)\left(\mathrm{Al}_{1.94} \mathrm{Fe}_{0.06}\right) \mathrm{Si}_{4} \mathrm{BO}_{15}(\mathrm{OH})(Z=2)$ \\
Wavelength & $0.71069 \AA$ \\
Device & Rigaku R-AXIS RAPID \\
Method & Oscillation \\
Crystal system & Triclinic \\
Space group & $P \overline{1}$ \\
Cell constants & $a=7.1488(4) \AA, \alpha=91.708(6)^{\circ}$ \\
& $b=9.1970(4) \AA, \beta=98.099(6)^{\circ}$ \\
& $c=8.9688(3) \AA, \gamma=77.201(5)^{\circ}$ \\
Volume & $569.29(4) \AA^{3}$ \\
Density (calculated) & $3.317 \mathrm{Mg} / \mathrm{m}^{3}$ \\
Absorption coefficient & $2.816 \mathrm{~mm}-1$ \\
Theta range & 3.23 to $30.50^{\circ}$ \\
Index ranges & $-10 \leq h \leq 10,-11 \leq k \leq 13,-12 \leq l \leq 12$ \\
Measured reflections & 7131 \\
$R_{\text {int }} / R_{\text {sigma }}$ & $0.0362 / 0.0279$ \\
Data/parameters & $3431 / 236$ \\
Godddness of fit in $F^{2}$ & 1.23 \\
Exintiction parameter & $0.0160(17)$ \\
$R$ indeices $I>2$ & $R 1=0.0319, w R 2=0.0852^{*}$ \\
$R$ indices (all data) & $R 1=0.0431, w R 2=0.0885^{*}$ \\
Diff. peak and hole & 0.797 and $-0.815 \mathrm{e} / \AA^{3}$ \\
\hline${ }^{*}=1 /\left[\sigma^{2}\left(F_{\mathrm{o}}{ }^{2}\right)+(0.0447 P)^{2}+0.1257 P\right]$ where $P=\left(F_{\mathrm{o}}{ }^{2}+2 F_{\mathrm{c}}{ }^{2}\right) / 3$. \\
\end{tabular}

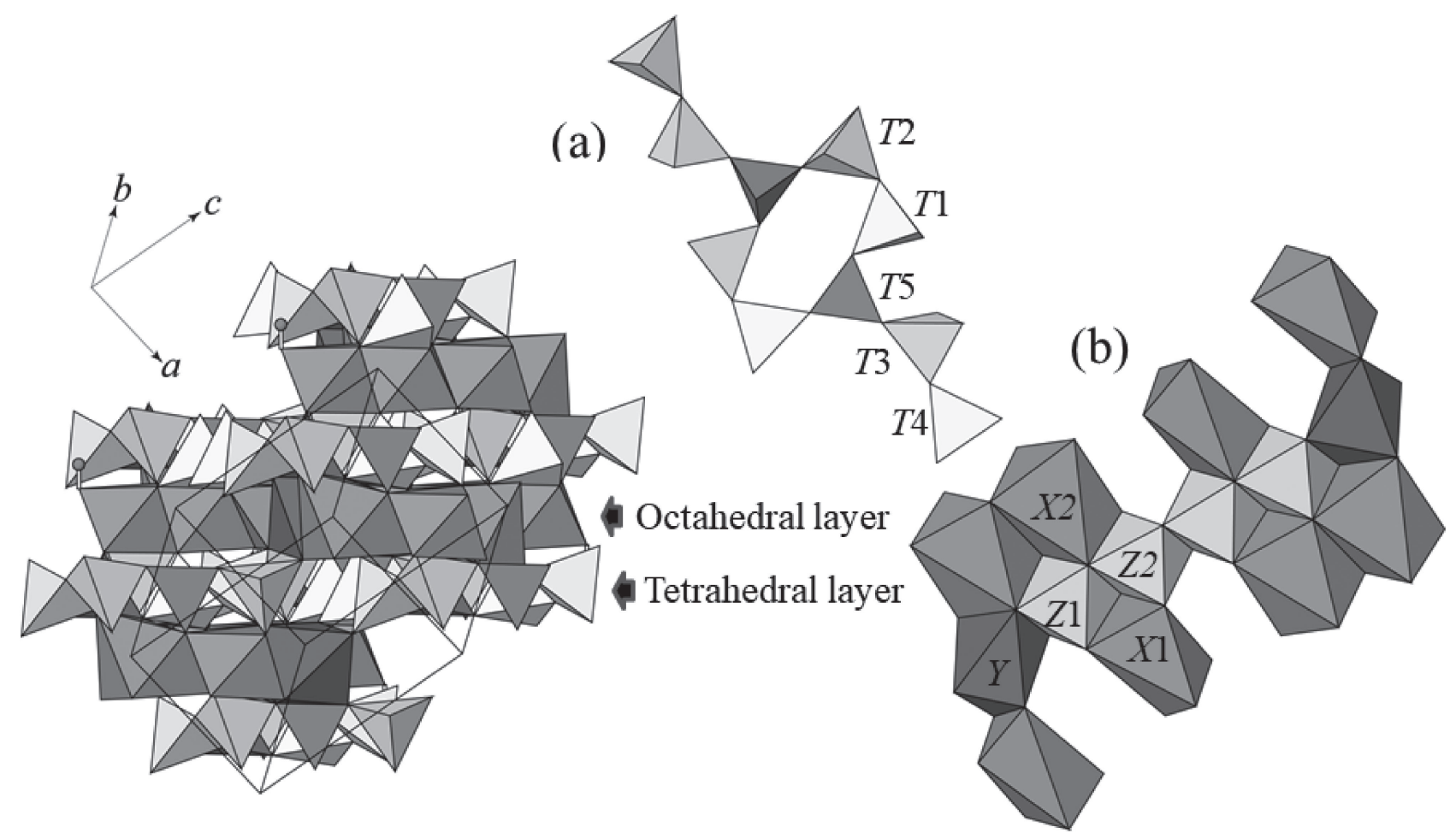

Figure 1. The crystal structure of axinite with (a) a tetrahedral layer of a $T 5_{2}(T 1, T 2, T 3, T 4)_{8} \mathrm{O}_{30}$ planar unit and (b) an octahedral sequence of $Y-Z 1-Z 2-Z 2-Z 1-Y$ with $X 1$ and $X 2$ (Dowty, 2006). Color version is available online from https://doi.org/10.2465/jmps.190110. 
Table 3. Atomic positions and equivalent displacement parameters of axinite-( $\mathrm{Fe})$ from Nand-C

\begin{tabular}{llrrrr}
\hline Site & Occupation & $x$ & $y$ & $z$ & $U_{\text {eq }}$ \\
\hline$X 1$ & $\mathrm{Ca}$ & $0.7461(1)$ & $0.3481(1)$ & $0.3953(1)$ & $0.0096(1)$ \\
$X 2$ & $\mathrm{Ca}$ & $0.1827(1)$ & $0.1007(1)$ & $0.0842(1)$ & $0.0100(1)$ \\
$Y$ & $\mathrm{Fe}_{0.565} \mathrm{Mn}_{0.33} \mathrm{Mg}_{0.08} \mathrm{Ca}_{0.025}$ & $0.7683(1)$ & $0.5907(1)$ & $0.1122(1)$ & $0.0102(1)$ \\
$Z 1$ & $\mathrm{Al}_{0.94} \mathrm{Fe}_{0.06}$ & $0.0525(1)$ & $0.8011(1)$ & $0.2537(1)$ & $0.0055(2)$ \\
$Z 2$ & $\mathrm{Al}$ & $0.3519(1)$ & $0.9362(1)$ & $0.4210(1)$ & $0.0045(1)$ \\
$T 1$ & $\mathrm{Si}$ & $0.2115(1)$ & $0.4502(1)$ & $0.2350(1)$ & $0.0062(2)$ \\
$T 2$ & $\mathrm{Si}$ & $0.2193(1)$ & $0.2747(1)$ & $0.5236(1)$ & $0.0056(2)$ \\
$T 3$ & $\mathrm{Si}$ & $0.6995(1)$ & $0.2558(1)$ & $0.0116(1)$ & $0.0061(2)$ \\
$T 4$ & $\mathrm{Si}$ & $0.6413(1)$ & $0.0192(1)$ & $0.2302(1)$ & $0.0057(2)$ \\
$T 5$ & $\mathrm{~B}$ & $0.4615(4)$ & $0.6349(3)$ & $0.2866(3)$ & $0.0063(5)$ \\
$\mathrm{O} 1$ & $\mathrm{O}$ & $0.0555(3)$ & $0.6034(2)$ & $0.1900(2)$ & $0.0086(4)$ \\
$\mathrm{O} 2$ & $\mathrm{O}$ & $0.2328(3)$ & $0.3385(2)$ & $0.0967(2)$ & $0.0113(4)$ \\
$\mathrm{O} 3$ & $\mathrm{O}$ & $0.4193(3)$ & $0.4871(2)$ & $0.3123(2)$ & $0.0083(4)$ \\
$\mathrm{O} 4$ & $\mathrm{O}$ & $0.1364(3)$ & $0.3735(2)$ & $0.3708(2)$ & $0.0120(4)$ \\
$\mathrm{O} 5$ & $\mathrm{O}$ & $0.0218(3)$ & $0.2421(2)$ & $0.5637(2)$ & $0.0086(4)$ \\
$\mathrm{O} 6$ & $\mathrm{O}$ & $0.3269(3)$ & $0.3793(2)$ & $0.6455(2)$ & $0.0077(4)$ \\
$\mathrm{O} 7$ & $\mathrm{O}$ & $0.3806(3)$ & $0.1274(2)$ & $0.4957(2)$ & $0.0071(4)$ \\
$\mathrm{O} 8$ & $\mathrm{O}$ & $0.5371(3)$ & $0.3436(2)$ & $0.8770(2)$ & $0.0086(4)$ \\
$\mathrm{O} 9$ & $\mathrm{O}$ & $0.8765(3)$ & $0.1544(2)$ & $0.9338(2)$ & $0.0077(4)$ \\
$\mathrm{O} 10$ & $\mathrm{O}$ & $0.7692(3)$ & $0.3660(2)$ & $0.1395(2)$ & $0.0108(4)$ \\
$\mathrm{O} 11$ & $\mathrm{O}$ & $0.6039(3)$ & $0.1347(2)$ & $0.0871(2)$ & $0.0114(4)$ \\
$\mathrm{O} 12$ & $\mathrm{O}$ & $0.4365(3)$ & $0.9816(2)$ & $0.2439(2)$ & $0.0079(4)$ \\
$\mathrm{O} 13$ & $\mathrm{O}$ & $0.7212(3)$ & $0.0996(2)$ & $0.3844(2)$ & $0.0076(4)$ \\
$\mathrm{O} 14$ & $\mathrm{O}$ & $0.7939(3)$ & $0.8748(2)$ & $0.1776(2)$ & $0.0088(4)$ \\
$\mathrm{O} 15$ & $\mathrm{O}$ & $0.3255(3)$ & $0.7469(2)$ & $0.3550(2)$ & $0.0065(4)$ \\
$\mathrm{O} 16$ & $\mathrm{O}$ & $0.0972(3)$ & $0.9955(2)$ & $0.3228(2)$ & $0.0079(4)$ \\
$\mathrm{H} 16{ }^{*}$ & $\mathrm{H}$ & 0.0071 & 1.0404 & 0.3644 & 0.012 \\
\hline
\end{tabular}

${ }^{*}$ See text

Nan-C. Additionally, the averaged $75-\mathrm{O}$ bond length $(1.486 \AA)$ could be a sufficient reason for the full occupation of $\mathrm{B}$ at the $T 5$ site. The converged isotropic displacement parameter of the $Z 1$ site was obviously smaller than that of the $Z 2$ site. This may indicate the possible distribution of a heavy metal cation at the $Z 1$ site. Finally, the structural information obtained by AXS and XANES analysis allows us to make a final structural model, and the full-matrix least-squares refinement of all parameters converged at $R=0.0319$ for the observed 3016 reflections. The anisotropic displacement model was introduced for non-hydrogen atoms, and the isotropic displacement parameter of $U_{\text {iso }}(\mathrm{H} 16)=1.5 U_{\text {eq }}(\mathrm{O} 16)$ was used for H16 in the refinement. Final atomic coordinates, together with the equivalent displacement parameters and the anisotropic displacement parameters, are shown in Tables 3 and 4, respectively.

\section{RESULTS AND DISCUSSION}

\section{Chemical composition of axinite-(Fe) sample}

The chemical composition of Nan-C is relatively homogenous in comparison with the other two axinite- $(\mathrm{Fe})$ samples, and its octahedral sites are occupied by $3.98<$ $\mathrm{Ca}<4.08,1.18<\mathrm{Fe}<1.33,0.55<\mathrm{Mn}<0.75,3.85<$ $\mathrm{Al}<3.91$, and $0.11<\mathrm{Mg}<0.25$, and a negligible amount of $\mathrm{Ti}, \mathrm{Na}$, and $\mathrm{K}$ (all in apfu). Because the ordinary single-crystal structural analysis of Nan-C indicates the full occupation of $\mathrm{Si}$ at the $T 1, T 2, T 3$, and $T 4$ sites and the stoichiometric distribution of $\mathrm{B}$ at the $T 5$ site, the present analysis normalizes the number of each element in the octahedral sites to meet the equation $\Sigma_{a p f u}(\mathrm{Ca}+\mathrm{Mn}+$ $\mathrm{Fe}+\mathrm{Al}+\mathrm{Mg})=10$. The averaged numbers of these cations are listed in Table 1 together with their standard deviations in brackets. The structural formula of axinite(Fe) for Nan-C could be described as $\mathrm{Ca}_{2}\left(\mathrm{Fe}_{0.565} \mathrm{Mn}_{0.33}\right.$ $\left.\mathrm{Mg}_{0.08} \mathrm{Ca}_{0.025}\right)\left(\mathrm{Al}_{1.94} \mathrm{Fe}_{0.06}\right) \mathrm{Si}_{4} \mathrm{BO}_{15}(\mathrm{OH})$ with a $\mathrm{Fe}^{3+} / \mathrm{Fe}$ ratio of 0.096 . The formula indicates the possible distribution of $\mathrm{Ca}$ at the $Y$ site; nevertheless, the present authors maintain a view that the experimental error for the obtained $\mathrm{CaO}$ content led to this structural formula.

\section{Valence states of Mn and Fe}

The measured XANES spectra for Mn and Fe $K$-absorption edges are shown in Figures $2 \mathrm{a}$ and $2 \mathrm{~b}$, respectively. The XANES spectra of $\mathrm{Mn}$ for the three axinite- $(\mathrm{Fe})$ 
Table 4. Anisotropic displacement parameters of axinite-( $\mathrm{Fe})$ from Nan-C

\begin{tabular}{lllllll}
\hline Site & \multicolumn{1}{c}{$U_{11}$} & \multicolumn{1}{c}{$U_{22}$} & \multicolumn{1}{c}{$U_{33}$} & $U_{23}$ & $U_{31}$ & $U_{12}$ \\
\hline$X 1$ & $0.0107(3)$ & $0.0082(3)$ & $0.0089(3)$ & $0.0019(2)$ & $-0.0007(2)$ & $-0.0012(2)$ \\
$X 2$ & $0.0106(3)$ & $0.0098(3)$ & $0.0092(3)$ & $0.0024(2)$ & $-0.0028(2)$ & $-0.0036(2)$ \\
$Y$ & $0.0074(2)$ & $0.0137(2)$ & $0.0100(2)$ & $0.0028(2)$ & $0.0008(2)$ & $-0.0028(2)$ \\
$Z 1$ & $0.0059(3)$ & $0.0059(3)$ & $0.0050(3)$ & $0.0004(2)$ & $0.0007(2)$ & $-0.0016(3)$ \\
$Z 2$ & $0.0049(4)$ & $0.0047(4)$ & $0.0043(4)$ & $-0.0001(3)$ & $0.0004(3)$ & $-0.0017(3)$ \\
$T 1$ & $0.0071(3)$ & $0.0057(3)$ & $0.0057(3)$ & $0.0007(2)$ & $-0.0002(2)$ & $-0.0016(3)$ \\
$T 2$ & $0.0051(3)$ & $0.0057(3)$ & $0.0059(3)$ & $0.0002(2)$ & $0.0005(2)$ & $-0.0013(3)$ \\
$T 3$ & $0.0064(2)$ & $0.0065(2)$ & $0.0051(2)$ & $0.0012(1)$ & $0.0006(1)$ & $-0.0009(2)$ \\
$T 4$ & $0.0053(3)$ & $0.0065(3)$ & $0.0054(3)$ & $0.0005(2)$ & $0.0009(2)$ & $-0.0016(3)$ \\
$T 5$ & $0.0065(13)$ & $0.0070(13)$ & $0.0056(13)$ & $0.0002(9)$ & $0.0003(9)$ & $-0.0021(10)$ \\
O1 & $0.0094(9)$ & $0.0059(9)$ & $0.0100(9)$ & $0.0003(7)$ & $0.0001(7)$ & $-0.0015(7)$ \\
O2 & $0.0138(10)$ & $0.0099(10)$ & $0.0103(10)$ & $-0.0020(7)$ & $0.0020(7)$ & $-0.0026(8)$ \\
O3 & $0.0077(9)$ & $0.0065(9)$ & $0.0107(9)$ & $0.0014(7)$ & $-0.0003(7)$ & $-0.0022(7)$ \\
O4 & $0.0112(10)$ & $0.0151(10)$ & $0.0103(10)$ & $0.0060(7)$ & $-0.0001(7)$ & $-0.0044(8)$ \\
O5 & $0.0070(9)$ & $0.0121(10)$ & $0.0074(9)$ & $0.0015(7)$ & $0.0012(6)$ & $-0.0033(7)$ \\
O6 & $0.0054(9)$ & $0.0079(9)$ & $0.0099(9)$ & $-0.0021(7)$ & $-0.0001(6)$ & $-0.0025(7)$ \\
O7 & $0.0055(9)$ & $0.0073(9)$ & $0.0086(9)$ & $0.0001(7)$ & $0.0011(6)$ & $-0.0013(7)$ \\
O8 & $0.0089(9)$ & $0.0095(9)$ & $0.0067(9)$ & $0.0016(7)$ & $0.0019(7)$ & $0.0002(7)$ \\
O9 & $0.0074(9)$ & $0.0087(9)$ & $0.0063(9)$ & $-0.0002(7)$ & $0.0011(6)$ & $-0.0003(7)$ \\
O10 & $0.0122(10)$ & $0.0127(10)$ & $0.0076(9)$ & $-0.0016(7)$ & $0.0004(7)$ & $-0.0033(8)$ \\
O11 & $0.0120(10)$ & $0.0127(10)$ & $0.0104(10)$ & $0.0041(7)$ & $0.0015(7)$ & $-0.0042(8)$ \\
O12 & $0.0065(9)$ & $0.0103(9)$ & $0.0074(9)$ & $0.0010(7)$ & $0.0007(6)$ & $-0.0027(7)$ \\
O13 & $0.0081(9)$ & $0.0096(9)$ & $0.0060(9)$ & $-0.0006(7)$ & $0.0012(6)$ & $-0.0037(7)$ \\
O14 & $0.0081(9)$ & $0.0109(10)$ & $0.0073(9)$ & $-0.0011(7)$ & $0.0016(7)$ & $-0.0013(7)$ \\
O15 & $0.0062(9)$ & $0.0064(9)$ & $0.0068(9)$ & $-0.0005(6)$ & $0.0010(6)$ & $-0.0011(7)$ \\
O16 & $0.0071(9)$ & $0.0089(9)$ & $0.0075(9)$ & $-0.0012(7)$ & $0.0021(7)$ & $-0.0004(7)$ \\
\hline
\end{tabular}
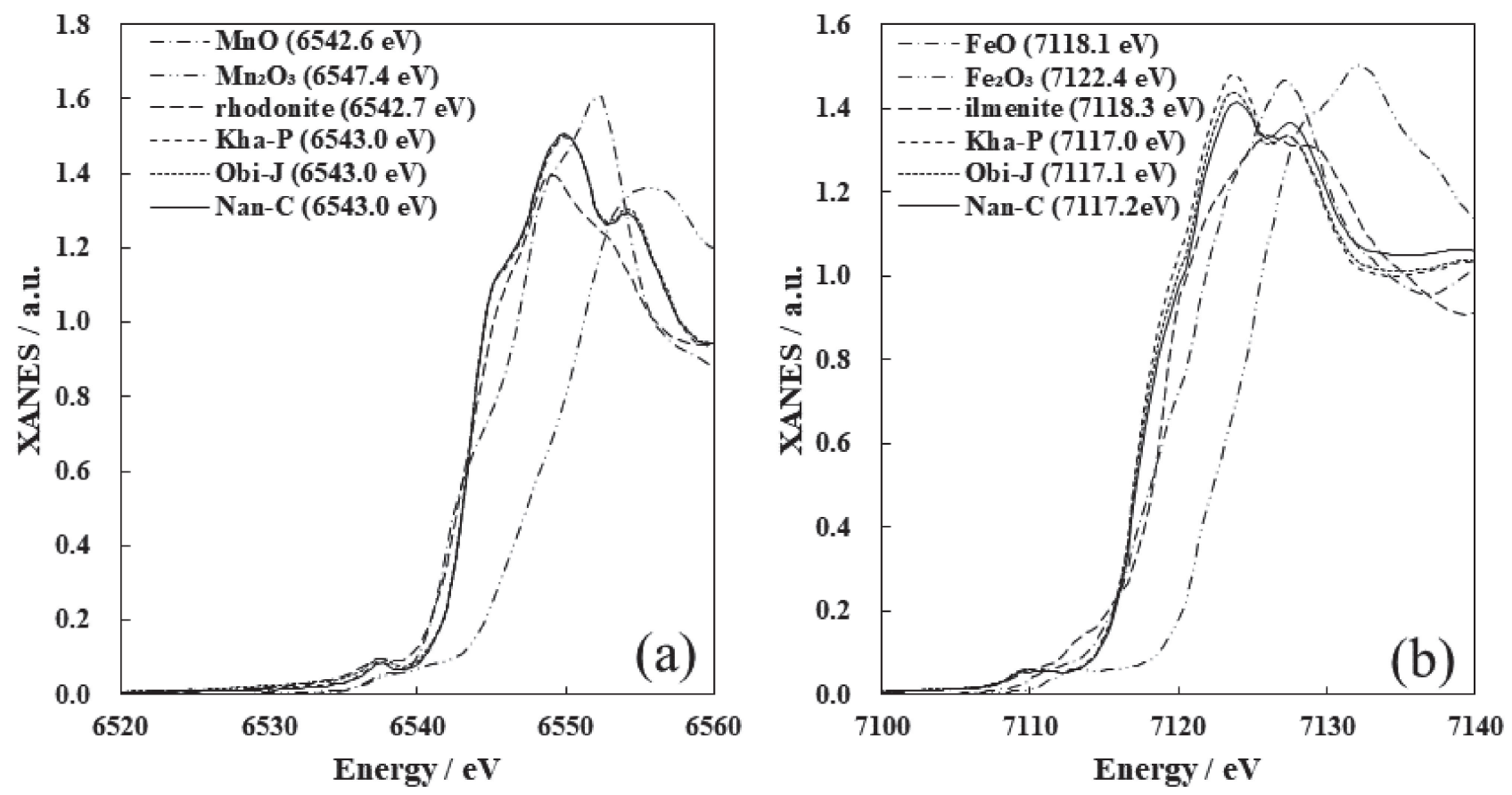

Figure 2. (a) $\mathrm{Mn}$ and (b) Fe $K$-edge XANES spectra of axinite- $(\mathrm{Fe})$ together with standard samples. The positions of the absorption edges shown in brackets were defined as half the normalized edge jump. 

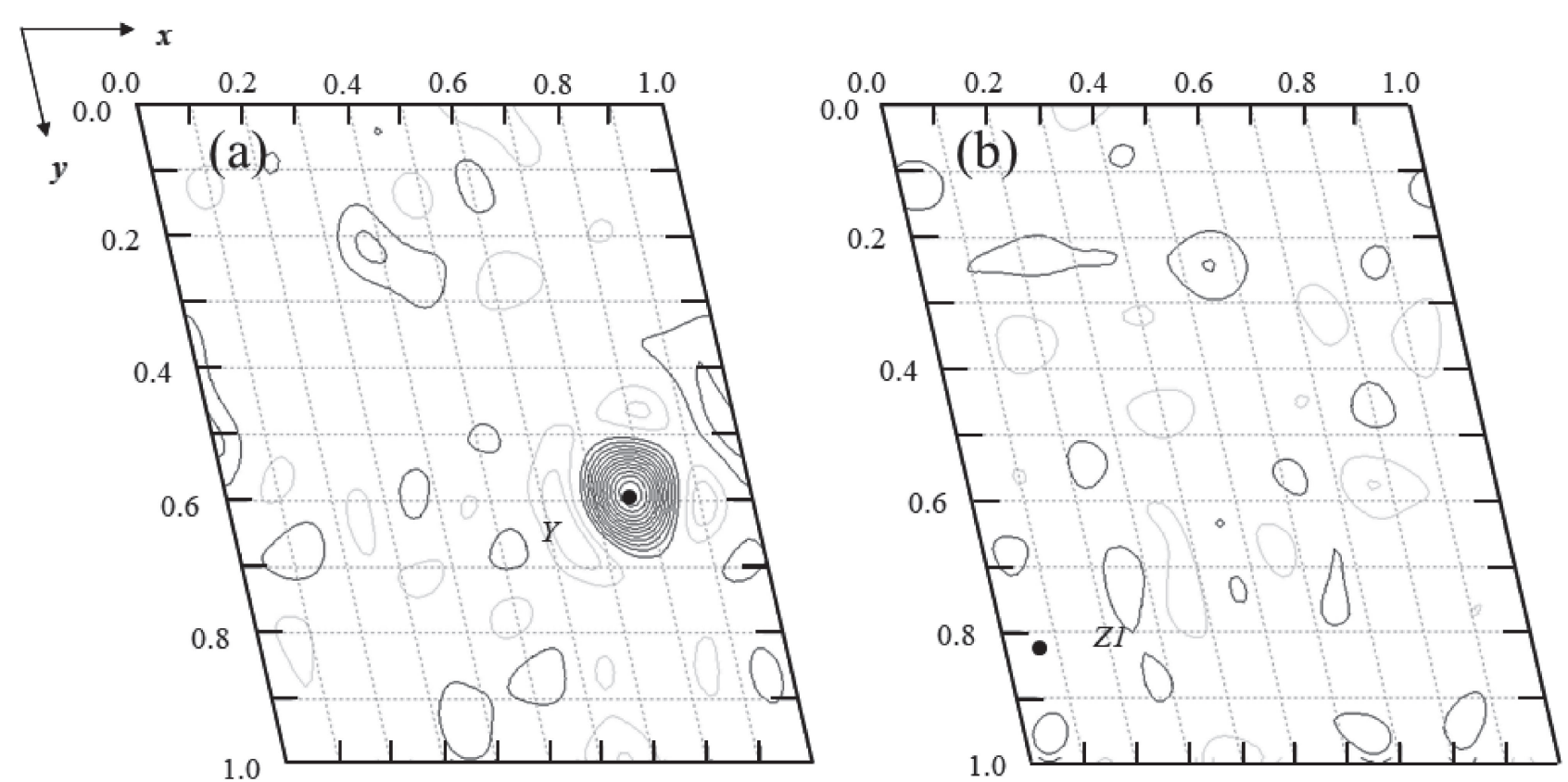

Figure 3. The Mn distribution maps at (a) $z=0.11$ and (b) $z=0.26$ analyzed by AXS measurement at the Mn $K$-absorption edge. The contours are drawn at an interval of $0.14 e / \AA^{3}$ : negative contours are in broken lines, while zero-contours are omitted.

samples are almost superimposed, and their edge positions are similar to those of rhodonite and $\mathrm{MnO}$. This result readily suggests that most of the Mn atoms in axinite- $(\mathrm{Fe})$ are in a divalent state and provides a reasonable agreement with the general discussion of $\mathrm{Mn}$ in the axinite structure. In the case of Fe-XANES, the edge positions for the axinite- $(\mathrm{Fe})$ samples are located near those of ilmenite and $\mathrm{FeO}$, suggesting the overall preference for divalent $\mathrm{Fe}^{2+}$. However, the edge positions shift toward the higher energy side in the order Kah-P, Obi-J, and Nan-C. This shift suggests an increase in the $\mathrm{Fe}^{3+}$ fraction as a substitute for $\mathrm{Al}^{3+}$. The relationship between $\mathrm{Fe}^{3+}$ and $\mathrm{Al}$ in the axinite structure is attributed well to the discussion found in the previous literature (Andreozzi et al., 2000a, 2004).

\section{Distribution map of Mn and Fe obtained by AXS measurements}

Classical single-crystal X-ray diffraction is one of the most powerful tools for determining the atomic distribution in crystals. However, the discrimination of $\mathrm{Mn}$ and $\mathrm{Fe}$ is very difficult only using ordinary $\mathrm{X}$-ray diffraction because the atomic scattering factors for $\mathrm{Mn}$ and $\mathrm{Fe}$ are similar to each other. Anomalous X-ray scattering at energies near the absorption edge is one way to circumvent this difficulty by analyzing an appropriate difference in the measured structure factors (Wulf, 1990; Sugiyama et al., 2010; Togashi et al., 2011). Figures 3a and 3b show the distribution map for Mn at $z=0.11$ and 0.26 obtained by Fourier synthesis of the difference in structure factors measured at the Mn $K$-absorption edge. The distribution of Mn can be observed at the $Y$ site, whereas it is not found at the $Z 1$ site. These feature simply the preferred distribution of $\mathrm{Mn}$ at the $Y$ site. Figures $4 \mathrm{a}$ and $4 \mathrm{~b}$ show the distribution map for $\mathrm{Fe}$ at $z=0.11$ and 0.26 obtained by Fourier synthesis of the difference in structure factor measured at the $\mathrm{Fe} K$-absorption edge. Although the anomalous dispersion terms of $\mathrm{Mn}$ just below the $\mathrm{Fe}$ $K$-absorption edge more or less contribute to the distribution map of $\mathrm{Fe}$, the effect is expected to produce a negative peak at the $Y$ site where $\mathrm{Mn}$ resides. Therefore, the distinct positive peaks at the $Y$ site and $Z 1$ site definitely imply the distribution of Fe at these sites. It should be noted that we could find no significant contribution at the $X 2$ site in the distribution map of $\mathrm{Mn}$ and at the $Z 2$ site in the distribution map of Fe. These findings allow us to make a superior structural model in which the $X 2$ and $Z 2$ sites are fully occupied by $\mathrm{Ca}$ and $\mathrm{Al}$, respectively.

\section{Single-crystal $\mathrm{X}$-ray diffraction}

Thanks to the structural information acquired from EXAFS and AXS measurements together with the ordinary single crystal X-ray diffraction, the structural refinement could be performed using the reasonable structural model with the complete occupancy of the $T 1$ to $T 4$ sites by $\mathrm{Si}$, of the $T 5$ site by $\mathrm{B}$, of the $X 1$ and $X 2$ sites by $\mathrm{Ca}$, and of 

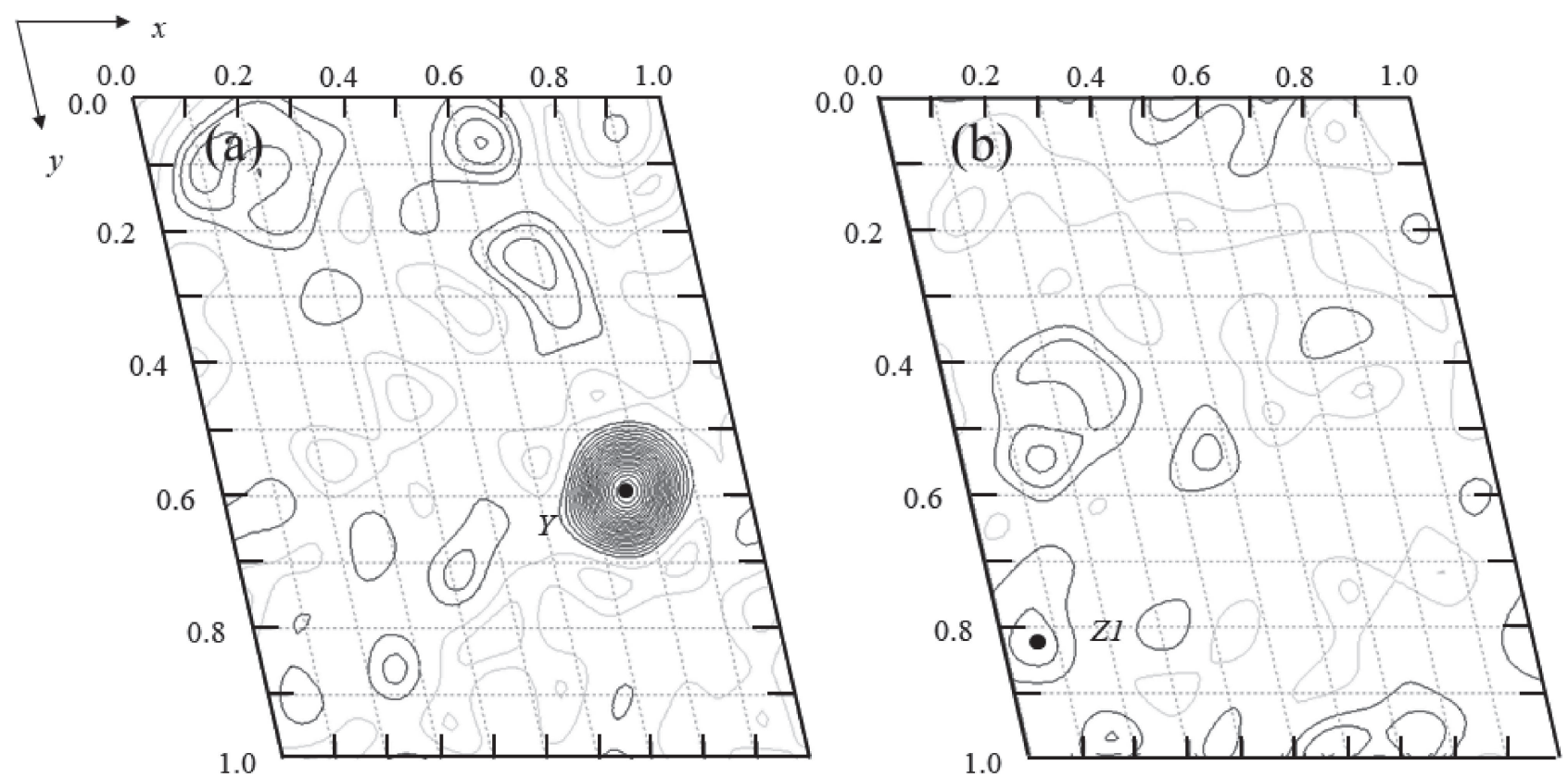

Figure 4. The Fe distribution maps at (a) $z=0.11$ and (b) $z=0.26$ analyzed by AXS measurement at the Fe $K$-absorption edge. The contours are drawn at an interval of $0.14 e / \AA^{3}$ : negative contours are in broken lines, while zero-contours are omitted.

Table 5. Interatomic distances $(\AA)$ and site volume $\left(\AA^{3}\right)$ of tetrahedral sites

\begin{tabular}{lccccc}
\hline & $T 1$ & $T 2$ & $T 3$ & $T 4$ & $T 5$ \\
\hline O1 & $1.613(2)$ & & & & \\
O2 & $1.589(2)$ & & & & $1.487(3)$ \\
O3 & $1.649(2)$ & & & & \\
O4 & $1.635(2)$ & $1.631(2)$ & & & \\
O5 & & $1.597(2)$ & & & $1.528(3)$ \\
O6 & & $1.655(2)$ & & & \\
O7 & & $1.611(2)$ & & & $1.488(3)$ \\
O8 & & & $1.645(2)$ & & \\
O9 & & & $1.626(2)$ & & \\
O10 & & & $1.608(2)$ & & \\
O11 & & & $1.637(2)$ & $1.645(2)$ & \\
O12 & & & & $1.599(2)$ & \\
O13 & & & & $1.640(2)$ & \\
O14 & & & & $1.626(2)$ & \\
O15 & & & & & $1.439(3)$ \\
O16 & & & & & \\
\hline Average & 1.622 & 1.624 & 1.629 & 1.628 & 1.486 \\
Volume & 2.18 & 2.17 & 2.21 & 2.20 & 1.67 \\
\hline
\end{tabular}

the $Z 2$ site by Al. The constituents for the $Y$ site and $Z 1$ site were fixed as $\mathrm{Fe}_{0.565} \mathrm{Mn}_{0.33} \mathrm{Mg}_{0.08} \mathrm{Ca}_{0.025}$ and $\mathrm{Al}_{0.94}$ $\mathrm{Fe}_{0.06}$, respectively, using the chemical information listed in Table 1. Because the structural features of Nan-C are similar to those of axinite in Figure 1, the detailed interatomic distances associated with the elemental distribution are discussed in this paper. Interatomic distances for octahedral and tetrahedral sites are summarized in Tables 5 and 6 , along with calculated site volumes.
Table 6. Interatomic distances $(\AA)$ and volume $\left(\AA^{3}\right)$ of octahedral sites

\begin{tabular}{|c|c|c|c|c|c|}
\hline & $X 1$ & $X 2$ & $Y$ & $Z 1$ & $Z 2$ \\
\hline$\overline{\mathrm{O} 1}$ & & & $2.101(2)$ & $1.887(2)$ & \\
\hline $\mathrm{O} 2$ & & $2.290(2)$ & $2.000(2)$ & & \\
\hline $\mathrm{O} 3$ & $2.427(2)$ & & & & \\
\hline $\mathrm{O} 4$ & & & & & \\
\hline O5 & $2.348(2)$ & & & $1.871(2)$ & \\
\hline O6 & $2.473(2)$ & & $2.358(2)$ & & \\
\hline $\mathrm{O} 7$ & & & & & $\begin{array}{l}1.907(2) \\
1.919(2)\end{array}$ \\
\hline O8 & & & $2.147(2)$ & & \\
\hline O9 & & $\begin{array}{l}2.363(2) \\
2.472(2)\end{array}$ & & $1.905(2)$ & \\
\hline $\begin{array}{l}\mathrm{O} 10 \\
\mathrm{O} 11\end{array}$ & $2.336(2)$ & & $2.087(2)$ & & \\
\hline $\mathrm{O} 12$ & & $2.242(2)$ & & & $1.867(2)$ \\
\hline $\mathrm{O} 13$ & $2.330(2)$ & & & & $1.948(2)$ \\
\hline $\mathrm{O} 14$ & & $2.398(2)$ & $2.701(2)$ & & \\
\hline $\mathrm{O} 15$ & $2.585(2)$ & & & $1.995(2)$ & $1.862(2)$ \\
\hline 016 & & $2.578(2)$ & & $1.953(2)$ & $1.878(2)$ \\
\hline Average & 2.417 & 2.390 & 2.232 & 1.922 & 1.897 \\
\hline Volume & 15.50 & 15.39 & 13.30 & 9.24 & 9.04 \\
\hline
\end{tabular}

As shown in Figure 1, the $X 1$ and $X 2$ sites for $\mathrm{Ca}$ indicate a significant distortion, and the geometry of $X 1$ could be described as a trigonal-antiprism rather than the common octahedron, in particular (Takéuchi et al., 1974). The $X 2$ site is smaller than the $X 1$ site, and the excess amount of Mn was suggested to reside at this site (Basso et al., 1973; Belokoneva et al., 1997, 2001). However, the 
present EPMA analysis of Nan-C suggests the full occupation of $\mathrm{Ca}$ at the $X 2$ site, and the introduction of a chemically disordered model for $\mathrm{Ca} / \mathrm{Mn}$ at this site did not improve the results of the structural refinement. This conclusion is also supported by AXS analysis with respect to the Mn distribution.

The averaged $Y$-O distance is $2.232 \AA$, and the longest $Y-\mathrm{O}(14)$ bond is $2.701 \AA$. This heavily distorted feature of octahedra is common to every axinite structure. The averaged distance is associated with the effective ionic radius of constituent elements, and the mean $Y-\mathrm{O}$ distance $(2.232 \AA)$ and polyhedron volume at the $Y$ site $\left(13.30 \AA^{3}\right)$ of Nan-C are larger than that of the end-member axinite-(Mg) (12.56 $\left.\AA^{3}\right)$ (Andreozzi et al., 2000b). Similarly, the averaged $Y$-O distance indicates close similarity with those of axinite- $(\mathrm{Fe})$ No.30 and No.35, with the $Y$ site filled by $\mathrm{Fe}_{0.67} \mathrm{Mn}_{0.205} \mathrm{Mg}_{0.12} \mathrm{Al}_{0.005}$ and $\mathrm{Fe}_{0.425}$ $\mathrm{Mn}_{0.37} \mathrm{Mg}_{0.195}$, respectively (Andreozzi et al., 2004). The unit-cell parameters in Table 2 are close to the published values for the typical axinite-( $\mathrm{Fe})$ samples, indicating a relatively smaller volume in comparison with axinite(Mn). This is also attributed to the presence of smaller divalent cations of $\mathrm{Fe}$ and $\mathrm{Mg}$ at the $Y$ site of axinite-(Fe) (Andreozzi et al., 2000a, 2004).

The averaged distances for the $Z 1$ and $Z 2$ sites are $1.922 \AA$ and $1.897 \AA$, respectively. Because the averaged size of $1.906 \AA$ and $1.894 \AA$ with full occupation of Al sites were reported in axinite-( $\mathrm{Mg}$ ) (Andreozzi et al., 2000b), the larger averaged distance and the corresponding volume of the $Z 1$ site for Nan-C are consistent with the partial occupation of $\mathrm{Fe}$ at the $Z 1$ site. It may be noted that further structural refinement with a mixed occupation model of $\mathrm{Al} / \mathrm{Fe}$ at the $Z 2$ site suggested no significant occupation of $\mathrm{Fe}$ at the $Z 2$ site.

The averaged distances for the $T 1$ to $T 4$ sites with $\mathrm{Si}$ range between 1.622 and $1.628 \AA$, corresponding well with the well-compiled data reported by Andreozzi et al. (2004). Similarly, no significant features those suggest the occupation of $\mathrm{Al}, \mathrm{Si}$ or Fe could be found in the local coordination features around the $T 5$ site. These structural features on tetrahedral sites support the stoichiometric distribution of $\mathrm{Si}$ and B in the structure of axinite- $(\mathrm{Fe})$ of Nan-C.

It should be added that a hydrogen position of $\mathrm{H} 16$ was safely determined in difference Fourier maps. H16 is bonded to $\mathrm{O} 16$ at $0.82 \AA$ and makes a hydrogen bridge with 013 with the distance of $2.77 \AA$ (Takéuchi et al., 1974; Swinnea et al., 1981; Belokoneva et al., 1997; Andreozzi et al., 2000b).

\section{CONCLUDING REMARKS}

The distribution of $\mathrm{Mn}$ and $\mathrm{Fe}$ in axinite-(Fe) from Nan- dan County, Hechi Prefecture, Guangxi Zhuang Autonomous Region, China was investigated by the two advanced analytical methods of XANES and AXS. The XANES spectra of axinite-(Fe) samples at $\mathrm{Mn}$ and $\mathrm{Fe}$ $K$-absorption edges indicate the overall preference for $\mathrm{Mn}^{2+}$ and $\mathrm{Fe}^{2+}$; however, the edge positions of the $\mathrm{Fe}$ $K$-absorption edge shift toward the high-energy side, in particular. This information and the results of EPMA allow us to suggest that the fractional $\mathrm{Fe}^{3+}$ content of axinite- $(\mathrm{Fe})$ increases as the $\mathrm{Al}$ content decreases. The elemental distribution maps of $\mathrm{Mn}$ and $\mathrm{Fe}$ obtained by AXS analysis clearly indicate the distribution of $\mathrm{Mn}$ at the $Y$ site and of Fe both at the $Y$ site and $Z 1$ site. The structural model with direct observation with respect to the distribution of $\mathrm{Mn}$ and $\mathrm{Fe}$ was subsequently employed for single-crystal X-ray diffraction, and the converged results were discussed along with previous data. The present authors would like to stress here that singlecrystal AXS analysis is concluded to be a very powerful tool for obtaining direct structural information concerning interesting elements, even though the next-neighboring atoms coexist in the structure.

\section{ACKNOWLEDGMENTS}

This research project was performed under the approval of the Photon Factory Program Advisory Committee (Proposal No. 2016G571).

\section{SUPPLEMENTARY MATERIAL}

Color version of Figure 1 is available online from https:// doi.org/10.2465/jmps. 190110.

\section{REFERENCES}

Andreozzi, G.B., Ottolini, L., Lucchesi, S., Graziani, G. and Russo, U. (2000a) Crystal chemistry of the axinite-group minerals: A multi-analytical approach. American Mineralogist, 85, 698706.

Andreozzi, G.B., Lucchesi, S. and Graziani, G. (2000b) Structural study of magnesioaxinite and its crystal-chemical relations with axinite-group minerals. European Journal of Mineralogy, $12,1185-1194$.

Andreozzi, G.B., Lucchesi, S., Graziani, G. and Russo, U. (2004) Site distribution of $\mathrm{Fe}^{2+}$ and $\mathrm{Fe}^{3+}$ in the axinite mineral group: New crystal-chemical formula. American Mineralogist, 89, 1763-1771.

Basso, R., Della Giusta, A. and Vlaic, G. (1973) La struttura della tinzenite. Periodico di Mineralogia, 42, 369-379.

Belokoneva, E.L., Pletnev, P.A. and Spiridonov, E.M. (1997) Crystal structure of low-manganese tinzenite (severginite). Crystallography Reports, 42, 934-937.

Belokoneva, E.L., Goryunova, A.N., Pletnev, P.A. and Spiridonov, E.M. (2001) Crystal structure of high-manganese tinzenite 
from the Falotta deposit in Switzerland. Crystallography Reports, 46, 30-32.

Dowty, E. (2006) ATOMS, shape Software. Kingsport, Tennessee, USA.

Farrugia, L.J. (2012) WinGX and ORTEP for Windows: an update. Journal of Applied Crystallography, 45, 849-854.

Grew, E.S. (1996) Borosilicates (exclusive of tourmaline) and Boron in Rock-forming Minerals in Metamorphic Environments. In Boron: Mineralogy, Petrology, and Geochemistry (Anovitz, L.M. and Grew, E.S. Eds.). Reviews in Mineralogy, 33, Mineralogical Society of America, 387-502.

Hirano, K., Ishikawa, T. and Kikuta, S. (1995) Development and application of X-ray phase retarders. Reviews of Scientific Instruments, 66, 1604-1609.

International Tables for Crystallography Volume C. (1992) Dordrecht: Kluwer Academic Publishers.

Lumpkin, G.R. and Ribbe, P.H. (1979) Chemistry and physical properties of axinites. American Mineralogist, 64, 635-645.

Ravel, B. and Newville, M. (2005) ATHENA, ARTEMIS, HEPHAESTUS: data analysis for X-ray absorption spectroscopy using IFEFFIT. Journal of Synchrotron Radiation, 12, $537-41$.

Sanero, E. and Gottardi, G. (1968) Nomenclature and crystalchemistry of axinites. American Mineralogist, 53, 1407-1411.

Sheldrick, G.M. (2008) A short history of SHELX. Acta Crystallographica, A64, 112-122.

Sugiyama, K., Genba, M., Hiraga, K. and Yokoyama, Y. (2010)
The structure of $Y-\mathrm{Al}_{13-x} \mathrm{Co}_{4}(x=0.8)$ analyzed by single crystal $\mathrm{X}$-ray diffraction with anomalous $\mathrm{X}$-ray scattering. Journal of Alloys and Compounds, 494, 98-101.

Swinnea, J.S., Steinfink, H., Rendon-DiazMiron, I.E. and Enciso De La Vega, S. (1981) The crystal structure of a Mexican axinite. American Mineralogist, 66, 428-431.

Takéuchi, Y., Ozawa, T., Ito, T., Zoltai, T. and Finney, J.J. (1974) The $\mathrm{B}_{2} \mathrm{Si}_{8} \mathrm{O}_{30}$ groups of tetrahedra in axinite and comments on the deformation of Si tetrahedra in silicates. Zeitschrift für Kristallographie - Crystalline Materials, 140, 5-6.

Togashi, N., Sugiyama, K., Yu, J., Qiu, S. and Terasaki, O. (2011) Single crystal structure analysis of the Se-incorporated mordenite, coupled with the anomalous X-ray scattering. Solid State Sciences, 13, 684-690.

Waseda, Y. (1984) Novel Application of Anomalous (Resonance) $\mathrm{X}$-ray Scattering for Structural Characterization of Disordered Materials. Springer-Verlag GmbH, Heidelberg.

Wulf, R. (1990) Experimental distinction of elements with similar atomic number using anomalous dispersion ( $\delta$ synthesis): an application of synchrotron radiation in crystal structure analysis. Acta Crystallographica, A46, 681-688.

Manuscript received January 10, 2019

Manuscript accepted January 6, 2020

Published online June 13, 2020

Manuscript handled by Takahiro Kuribayashi 